\title{
René Leriche (1879-1955): Innovator of vascular surgery
}

\author{
Siang Yong $\underline{\operatorname{Tan}}^{1}, \mathrm{MD}, \mathrm{JD}$, Erica $\underline{K w o k}^{2}$, BS
}

$\mathrm{H}$ istoric accounts of vascular surgery reflect a myriad of beliefs about the vascular system. Medical pioneers, such as Sushruta (an Indian surgeon predating Hippocrates), Galen and Ambroise Paré (a renowned French surgeon of the 16th century), had all described the use of ligatures as a way to control haemorrhage, but medical practice prior to the 1700s continued to prefer the use of boiling oil and chemical styptic to cauterise blood vessels. The coming of age in vascular surgery, incorporating scientific principles and careful haemostasis, can be traced to a handful of pioneers, among them a Frenchman named René Leriche.

\section{A SURGEON IN THE MAKING Born in 1879 in} the small village of Roanne, France, René Leriche was initially inclined toward a military career, but his humanism propelled him to study medicine at the University of Lyon. Upon graduation in 1906, he chose surgery and trained with many famous French surgeons, including Antonin Poncet, Mathieu Jaboulay, and Alexis Carrel, a Nobel Laureate who pioneered advances in vascular suture and transplant surgery. Leriche was especially impressed with American surgeons, the most influential being William Halsted of Johns Hopkins Hospital, who was famous for his insistence on the scientific method. Their ten-year friendship lasted throughout Halsted's life and was critical to Leriche's growth as a surgeon. Shortly after his first meeting with Halsted, Leriche wrote:

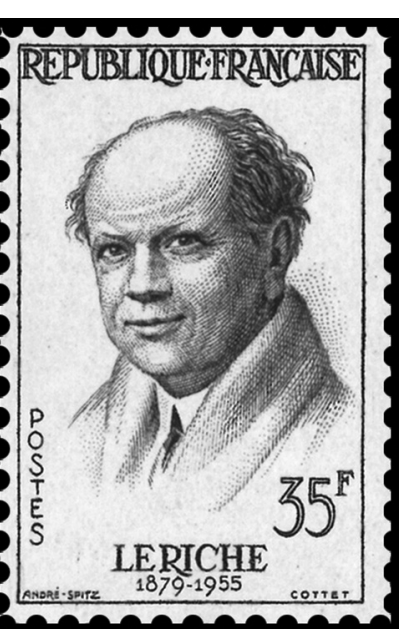

an American neurologist, had initially described this condition in soldiers who sustained nerve lacerations during the American Civil War. In 1917, Leriche described a patient who complained of permanent and painful paresthesia in the hand following a gunshot wound to the right axilla. There was no overt ischaemia to account for the symptoms. Based on the belief that arterial injury could also cause causalgia, he performed the first periarterial sympathectomy, which resulted in the patient experiencing dramatic relief 15 days later. Sympathectomy was subsequently found to be effective in various vasomotor disorders, Raynaud's disease and scleroderma. Today, however, its use is severely limited amidst newer therapeutic options.

EPONYMOUS RECOGNITION Shortly after he began his studies on sympathectomy, Leriche's research started to focus on ischaemia-induced leg pain, also known as claudication. In 1923 and again in 1940, he described a constellation of symptoms in male patients, which became known as Leriche syndrome or aortoiliac occlusive disease. The syndrome consists of the following triad: (a) absent or diminished femoral pulses; (b) intermittent claudication with pallor, coldness and diffuse muscle atrophy of both the lower extremities; and (c) impotence. Leriche believed that segmental atherosclerosis caused this syndrome and proposed that restoration of the blood supply could be curative. He had suggested, in the 1920s, 25 years before it was "In three days, I was completely changed by his spirit; I considered myself to be a different man, and I became an experimenter... The three days spent with him have always had a decisive influence on my conception of surgery. I try to model myself on him..."

THE STUDY OF PAIN During World War I, Leriche worked as a camp surgeon and witnessed numerous traumatic injuries. It was at this time that he first developed an interest in the sympathetic nervous system and its role in perpetuating pain in patients with nerve wounds and amputated stumps. He realised that pain, which "impoverishes man", was a symptom and not a disease, whose "morbid and pathologic manifestation (that) must be minimized, not respected." However, surgery texts in the early 20th century gave little or no attention to the subject of pain, and Leriche's unorthodox belief that the sympathetic nervous system was central to many pathological states invited ridicule. One of his innovations was the use of periarterial sympathectomy to relieve reflex sympathetic dystrophy or causalgia. Weir Mitchell, a conceivable therapy, that resection of the obliterated segment and repair with a vascular graft would be the ideal treatment for this syndrome. His prediction was vindicated in 1947 by his pupil Jean Kunlin, who successfully performed the first end-to-side anastomosis using an autogenous venous graft.

A PROLIFIC CAREER Leriche the surgeon would typically arrive at one of his clinics before $8 \mathrm{am}$ in a small but high-speed motorcar, quite often distracted and finding himself on the wrong side of the road, or looking backwards and talking to a passenger. Described as "small and round, gay and lively,... he would bounce out of his car with his assistants running behind trying to catch what he was saying." In 1924, he was appointed Professor of Clinical Surgery at Strasbourg in northeastern France, and in 1937, he became Professor of Experimental Medicine at the College de France in Paris, a prestigious position previously held by the likes of Magendie, Brown-Sequard and Claude Bernard. The prolific Leriche authored more than 1,400 publications

${ }^{1}$ Professor Emeritus of Medicine, University of Hawaii, ${ }^{2}$ Research carried out during 4th year medical student elective, John A Burns School of Medicine, University of Hawaii, Honolulu, USA

Correspondence: Prof Tan Siang Yong, 2226 Liliha Street, Suite B-104, Honolulu, HI 96817, USA. siang@hawaii.edu 
covering nearly every facet of surgery, and won countless awards and honorary degrees. However, he remained at heart the eternal curious observer and experimenter. One admirer described him in this way: "So acute are his powers of observation and deduction, so illuminating the flashes of inspiration which he directs upon his problems, that there are few_if any_surgeons of his generation who, having asked themselves 'why?' have been able to reply 'exactly thus' as often as has René Leriche."

Leriche was a charismatic teacher and public speaker who needed no notes. His pedagogical style was Socratic, allowing the questioner to answer his own question after redirection and prompting. He attracted many students, who later became famous themselves. They included Cid Dos Santos, a Portuguese vascular surgeon who performed the first successful thromboendarterectomy, Michael DeBakey, who performed the first successful carotid endarterectomy, and René Fontaine, a French surgeon who succeeded Leriche as Clinical Chair of Surgery. Famed American surgeon DeBakey aptly summarised Leriche in this fashion: "The high forehead, the clear blue, kind, but penetrating eyes, and the strong, determined chin vividly portray and reflect his keen sense of humor, his effervescing vivacity, his beneficent cordiality, his contagious enthusiasm, and his indomitable resoluteness. The spirit of camaraderie among his assistants, residents, and internes, the pervading atmosphere of enthusiasm in his clinic, and the worshipful admiration of his patients vividly exemplify the charming personality and the admirable characteristics of this great man."

THE MAN BEHIND THE MEDICINE Leriche was both a technical wizard and a Frenchman who loved French cuisine and fine wines. He was also an avid reader, and appreciated beautiful artwork; indeed, one of his patients was Henri Matisse, who sketched Leriche's portrait for his book
La Chirurgie, discipline de la connaissance (Surgery, Discipline of Knowledge). In the final years of his life, Leriche's failing health forced him to retreat to a small fishing port in the south of France, where he died at the age of 76 . In his honour, the International Society of Surgery established the prestigious René Leriche prize, awarded annually for outstanding contributions in the field of vascular science. Leriche was instrumental in creating a new breed of humanistic surgeons who took a physiological approach to surgery. Surgeons of the era often regarded an operation as a virtuoso performance, but Leriche promoted the view that the patient must be studied and treated as a whole person. He insisted on care and thoroughness, and was among the first to view disease as an alteration of normal physiology that caused anatomic change. Yet his greatest personal gift was not some syndrome or surgical technique but, as noted by one admirer, his dogged demonstration of "the magnificence of intellectual dynamism on the part of the surgeon."

\section{BIBLIOGRAPHY}

- Brunschwig A. Professor René Leriche. Cancer 1956; 9:75.

- Davies MK, Hollman A. René Henri Marie Leriche (1879-1955). Heart 1997; 77:98.

- Friedman SG. A History of Vascular Surgery. Mount Kisco, New York: Futura Publishing Company Inc, 1989.

- Jarrett F. René Leriche (1879-1955): father of vascular surgery. Surgery 1979; 86:736-41.

- Kieny R. René Leriche and his work. As time goes by. Ann Vasc Surg 1990; 4:105-11.

- René Leriche. Lancet 1956; 270:56-7.

- Rutkow IM, Rutkow BG, Ernst CB. Letters of William Halsted and René Leriche: "Our friendship seems so deep." Surgery 1980; 88:806-25.

- René Leriche. In Wikipedia [online]. Available at: http://en.wikipedia.org/ wiki/Ren\%C3\%A9_Leriche. Accessed March 13, 2008.

- Henri Matisse - Affordable signed lithograph - "René Leriche" [online]. Available at: http://www.ecademy.com/module.php?mod=list\&lid=42158. Accessed March 13, 2008.

- Silas Weir Mitchell. In Wikipedia [online] Available at: http://en.wikipedia. org/wiki/Silas_Weir_Mitchell. Accessed March 24, 2008. 